\title{
THE EFFECT OF EXTENSION OF THE HEAD AND NECK UPON THE INFRAHYOID RESPIRATORY PASSAGE AND THE SUPRACLAVICULAR PORTION OF THE HUMAN TRACHEA
}

\author{
BY \\ R. S. HARRIS \\ From the Department of Anatomy, University of Bristol
}

(RECEIVED FOR PUBLICATION JANUARY 19, 1959)

It is known from numerous studies (Macklin, 1925 ; Brückner, 1952; Holden and Ardran, 1957) that with a deep inspiratory movement the carina of the trachea descends about $2.5 \mathrm{~cm}$. The purpose of this paper is to report the effect of head and neck extension upon the supraclavicular portion of the trachea and infrahyoid respiratory passage. This investigation was part of a study of the function of tracheal extension in respiration.

\section{Material AND Method}

Fifteen healthy young adult males, aged 18 to 22 years, were studied by radiography. Lateral radiographs were taken of the cervical region so that the larynx, supraclavicular portion of the trachea, and medial end of the clavicle were visible on the radiographs. Four exposures (Figs. 1 to 4) were made with each subject ; first, with the head and neck in a slightly flexed position and the breath held in the phase of full inspiration; secondly, with the same posture but with the breath held in full expiration; thirdly, with the head and neck fully extended and the breath held in full inspiration; and, fourthly, in the extended posture but with the breath held in full expiration. The phases of full inspiration and full expiration were studied primarily to investigate the effect of head and neck extension upon the supraclavicular portion of the trachea when the trachea was already stretched (inspiratory phase) and not already stretched (expiratory phase). However, it was also found that significant changes in the anteroposterior diameter of the supraclavicular portion of the trachea were demonstrable during the phase of expiration, but which were not so apparent during inspiration. It was also felt that head and neck extension might affect the respiratory displacement of the larynx and this was investigated.

The posture of the subject was kept constant, only flexion and extension of the head and neck being allowed. The alignment of the subject to the $x$-ray beam and to the plate remained constant, which was achieved by fixing the subject's shoulders and head.
To compare the data between different individuals the measurements from the radiographs were corrected for geometrical distortion in the particular circumstances of each case. Thus $-b=\frac{a z+y c}{y+z}$ where

$\mathrm{a}=$ size of anode of $x$-ray tube

$\mathrm{b}=$ size of measurement in situ

$\mathrm{c}=$ size of measurement upon the radiograph

$y=$ distance from source of rays to cervical spinous processes

$\mathrm{Z}=$ distance from cervical spinous processes to $x$-ray plate

The following measurements were made:

(1) The distance from the level of the superior border of the hyoid bone to the inferior margin of the lamina of the thyroid cartilage, this distance being termed the "infrahyoid respiratory passage."

(2) The vertical distance from the level of the inferior margin of the thyroid lamina to the upper part of the medial end of the clavicle. This distance was considered to represent the vertical height of the supraclavicular part of the trachea, and changes in this vertical height could be directly compared with the vertical respiratory movement of the carina.

(3) The minimum antero-posterior diameter of the supraclavicular portion of the trachea.

(4) The respiratory displacement of the larynx from the phase of full expiration to full inspiration with the head flexed and then extended.

\section{RESUlTS}

(1) Effect of Head and Neck Extension UPON INFRAHYOID RESPIRATORY PASSAGE. During the phase of expiration, when the trachea is not extended inferiorly by descent of the lung root, extension of the head and neck caused the infrahyoid respiratory passage to become extended by about $23 \%$ of its initial length. The actual increase in length is about $0.9 \mathrm{~cm}$. (Table I).

During the phase of inspiration, when the trachea is extended inferiorly by the inferior 
TABLE I

EFFECT OF HEAD EXTENSION UPON LENGTH OF INFRAHYOID RESPIRATORY PASSAGE AND OF TRACHEA

\begin{tabular}{|c|c|c|c|c|c|c|c|c|}
\hline \multirow{3}{*}{ Case } & \multicolumn{4}{|c|}{ At Full Expiration } & \multicolumn{4}{|c|}{ At Full Inspiration } \\
\hline & \multicolumn{2}{|c|}{$\begin{array}{l}\text { Infrahyoid } \\
\text { Respiratory } \\
\text { Passage }\end{array}$} & \multicolumn{2}{|c|}{ Trachea } & \multicolumn{2}{|c|}{$\begin{array}{l}\text { Infrahyoid } \\
\text { Respiratory } \\
\text { Passage }\end{array}$} & \multicolumn{2}{|c|}{ Trachea } \\
\hline & $\begin{array}{c}\text { In- } \\
\text { crease } \\
\text { with } \\
\text { Ex- } \\
\text { tension } \\
\text { (cm.) }\end{array}$ & $\begin{array}{c}\% \\
\text { In- } \\
\text { crease }\end{array}$ & $\begin{array}{c}\text { In- } \\
\text { crease } \\
\text { with } \\
\text { Ex- } \\
\text { tension } \\
\text { (cm.) }\end{array}$ & $\begin{array}{c}\% \\
\text { In- } \\
\text { crease }\end{array}$ & \begin{tabular}{|} 
In- \\
crease \\
with \\
Ex- \\
tension \\
(cm.)
\end{tabular} & $\begin{array}{c}\% \\
\text { In- } \\
\text { crease }\end{array}$ & \begin{tabular}{|c|} 
In- \\
crease \\
with \\
Ex- \\
tension \\
(cm.)
\end{tabular} & $\begin{array}{c}\% \\
\text { In- } \\
\text { crease }\end{array}$ \\
\hline $\begin{array}{r}1 \\
2 \\
3 \\
4 \\
5 \\
6 \\
7 \\
8 \\
9 \\
10 \\
11 \\
12 \\
13 \\
14 \\
15\end{array}$ & $\begin{array}{l}0.63 \\
0.81 \\
0.81 \\
0.89 \\
0.80 \\
0.90 \\
1.50 \\
1.58 \\
0.90 \\
1.07 \\
0.80 \\
0.80 \\
0.72 \\
0.72 \\
0.18\end{array}$ & $\begin{array}{r}18.4 \\
20.9 \\
21.3 \\
25.5 \\
17.4 \\
33.3 \\
48.3 \\
39.3 \\
17.9 \\
25.3 \\
20.0 \\
22.9 \\
17.4 \\
17.8 \\
4.2\end{array}$ & $\begin{array}{l}2.24 \\
2.06 \\
1.17 \\
4.54 \\
2.13 \\
1.96 \\
0.72 \\
2.20 \\
3.76 \\
3.49 \\
3.28 \\
2.71 \\
3.49 \\
2.86 \\
2.67\end{array}$ & $\begin{array}{r}18.6 \\
17.1 \\
9.7 \\
37.8 \\
17.7 \\
16.5 \\
6.0 \\
18.3 \\
31.3 \\
29.0 \\
27.3 \\
22.6 \\
29.0 \\
23.8 \\
22.2\end{array}$ & $\begin{array}{l}1.34 \\
0.98 \\
0.63 \\
1.95 \\
0.18 \\
1.25 \\
1.18 \\
0.98 \\
2.33 \\
2.69 \\
0.53 \\
1.33 \\
0.35 \\
0.89 \\
0.54\end{array}$ & $\begin{array}{r}41.3 \\
22.2 \\
14.8 \\
58.9 \\
3.4 \\
39.6 \\
43.2 \\
17.7 \\
60.3 \\
78.8 \\
10.8 \\
33.1 \\
7.1 \\
21.1 \\
12.1\end{array}$ & $\begin{array}{l}0.98 \\
2.50 \\
1.98 \\
3.91 \\
2.48 \\
2.42 \\
3.35 \\
2.76 \\
5.55 \\
2.59 \\
2.58 \\
1.87 \\
1.97 \\
2.51 \\
2.23\end{array}$ & $\begin{array}{r}8.1 \\
20.8 \\
16.5 \\
32.5 \\
20.6 \\
20.1 \\
27.9 \\
23.0 \\
46.2 \\
21.5 \\
21.5 \\
15.6 \\
16.4 \\
20.9 \\
18.5\end{array}$ \\
\hline $\begin{array}{l}\text { Mean } \\
\text { S.E. }\end{array}$ & $\begin{array}{r}0.87 \\
\pm 0.08\end{array}$ & $\begin{array}{r}23 \cdot 3 \\
\pm 2 \cdot 6\end{array}$ & $\begin{array}{r}2.61 \\
\pm 0.25\end{array}$ & $\begin{array}{r}21 \cdot 7 \\
\pm 2 \cdot 1\end{array}$ & $\begin{array}{r}1 \cdot 14 \\
\pm 0.18\end{array}$ & $\begin{array}{r}30.9 \\
\pm 5.7\end{array}$ & $\begin{array}{r}2.64 \\
\pm 0.26\end{array}$ & $\begin{array}{r}22 \cdot 0 \\
\pm 2 \cdot 2\end{array}$ \\
\hline
\end{tabular}

displacement of the lung root, head and neck extension produced an increase in the length of the infrahyoid respiratory passage of $30.9 \%$ (about $1.1 \mathrm{~cm}$.).

It was felt that head and neck extension might produce greater extension of the infrahyoid respiratory passage during the inspiratory phase, since the trachea has then already been extended inferiorly and any further extension of the respiratory passages should preferentially occur above the level of the trachea. However, there is no statistical difference between the mean values in expiration $(23 \%$ and $0.9 \mathrm{~cm}$.) and those in inspiration $(30.9 \%$ and $1.1 \mathrm{~cm}$.). Presumably the infrahyoid respiratory passage is extended by stretching of the thyrohyoid membrane.

(2) EFFect of Head and Neck Extension upon Length of Supraclavicular Portion OF Trachea.-The "supraclavicular portion of the trachea" was taken as the distance between the level of the inferior margin of the lamina of the thyroid cartilage and the medial end of the clavicle. It includes that part of the respiratory passage related to the cricoid cartilage and the crico-tracheal membrane.

The slight difference (Table I) between the effects of head and neck extension in the phases of inspiration and expiration is not statistically significant. The vertical height of the upper end of the trachea was increased by about $2.6 \mathrm{~cm}$. in each case. Assuming the tracheal length to be
$12 \mathrm{~cm}$. (Testut and Latarjet, 1949), and that the position of the bifurcation remains constant with change of head posture, then the increase represents an extension of the trachea by $21-22 \%$. This is equivalent to the inferior inspiratory displacement of the carina occurring with a deep inspiratory movement.

(3) Effect of Head and Neck Extension UPON ANTERO-POSTERIOR DIAMETER OF SUPRAClavicular Portion of Trachea.-In the lateral radiographs the anterior and posterior walls of the trachea were clearly visible. There was a region of minimal antero-posterior diameter in each case ( 2 to $4 \mathrm{~cm}$. below the inferior margin of the lamina of the thyroid cartilage) and this was compared in the positions of flexion and extension.

Head and neck extension produced a significant $(P=<0.001)$ narrowing of the minimum anteroposterior diameter (Table II). The mean decrease in this diameter with head and neck extension was about $16 \%$ and in some cases as much as $36 \%$. The decrease appears to be due to forward displacement of the membranous portion of the tracheal wall, for, in the position of extension, a double outline at the posterior wall of the trachea was visible (Fig. 5). The effect of head and neck extension was much less apparent $(P=<0.05)$ when the measurements were made during the phase of full inspiration (Table II).

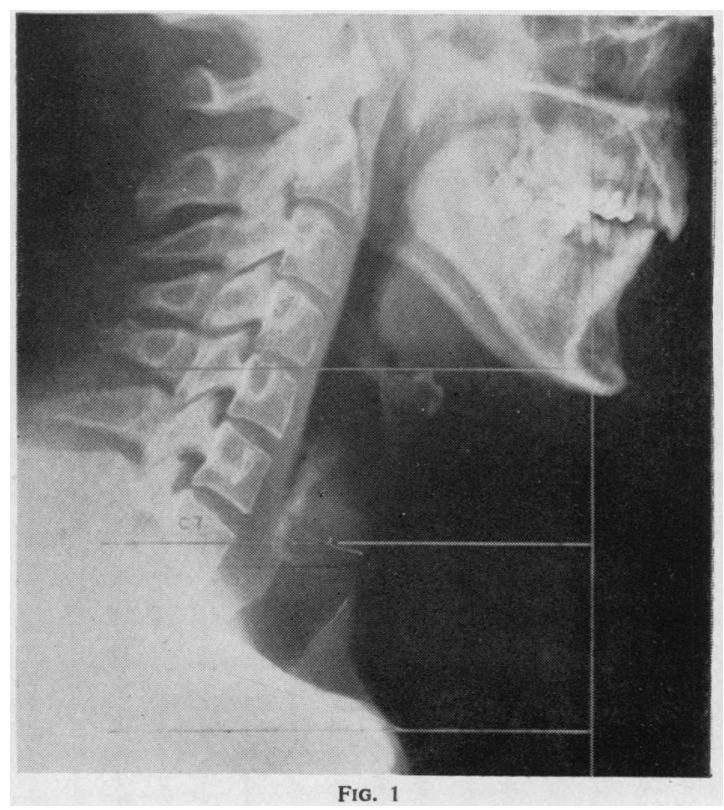




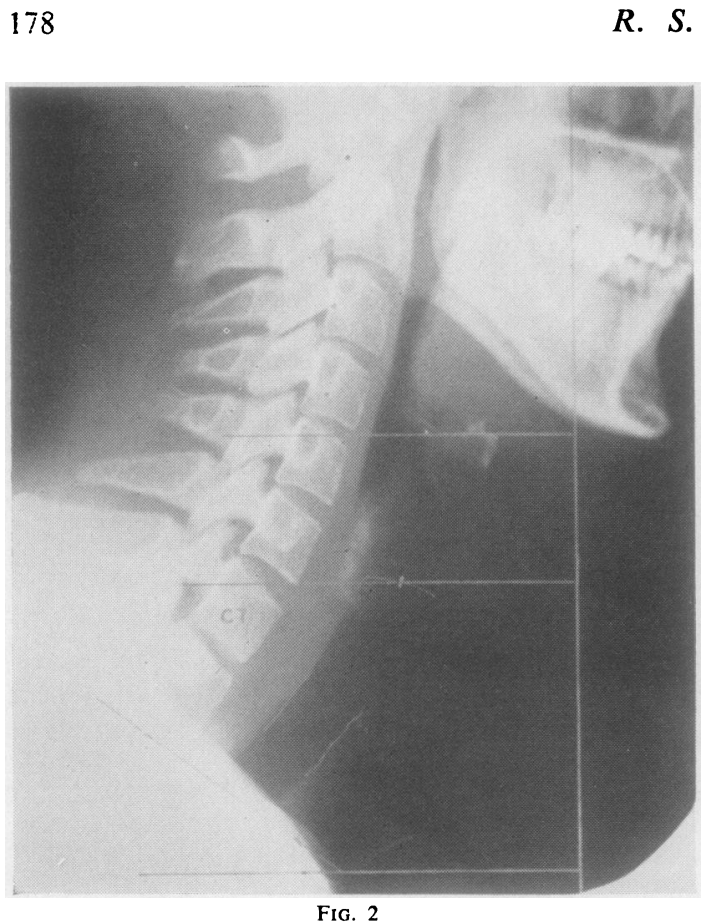

HARRIS

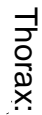

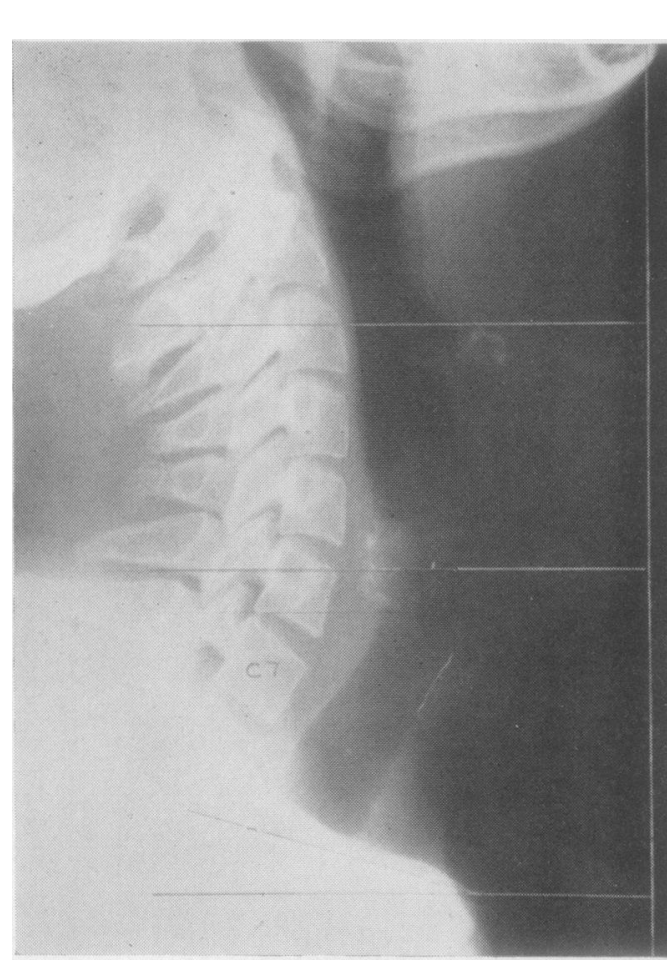

FIG. 3

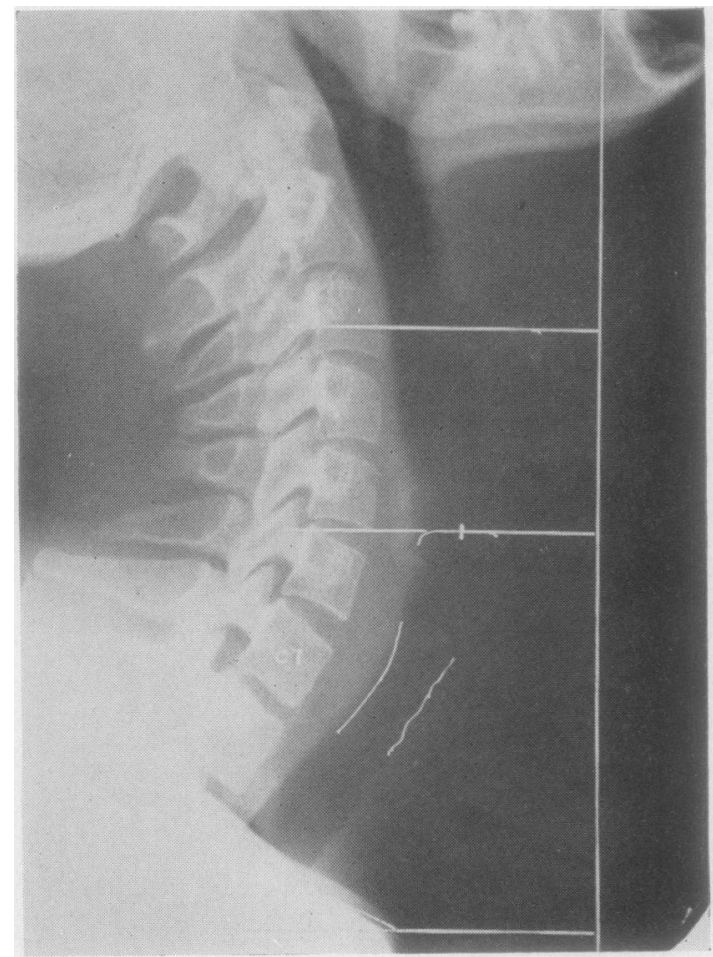

Fis. 4

Fio. 5

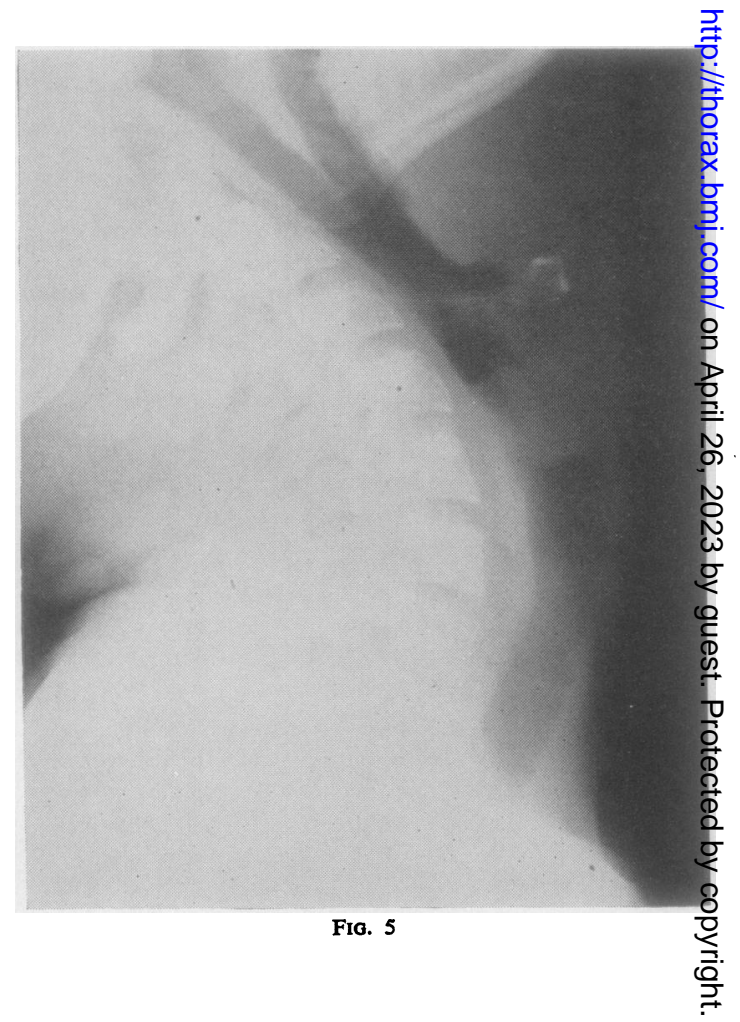


TABLE II

MINIMUM ANTERO-POSTERIOR DIAMETER OF TRACHEA (CM.)

\begin{tabular}{|c|c|c|c|c|c|c|c|c|}
\hline \multirow{2}{*}{ Case } & \multicolumn{4}{|c|}{ Full Expiration } & \multicolumn{4}{|c|}{ Full Inspiration } \\
\hline & Extended & Flexed & Difference & $\begin{array}{l}\% \text { Change } \\
\text { with Flexion }\end{array}$ & Extended & Flexed & Difference & $\begin{array}{l}\% \text { Change } \\
\text { with Flexion }\end{array}$ \\
\hline $\begin{array}{l}1 \\
2 \\
3 \\
4 \\
5 \\
6 \\
7 \\
8 \\
9 \\
10 \\
11 \\
12 \\
13 \\
14 \\
15\end{array}$ & $\begin{array}{l}1.36 \\
0.91 \\
1.05 \\
0.64 \\
1.53 \\
1.40 \\
1.37 \\
1.17 \\
1.18 \\
1.13 \\
1.04 \\
1.26 \\
1.27 \\
1.04 \\
1.22\end{array}$ & $\begin{array}{l}1.49 \\
0.96 \\
1.32 \\
1.00 \\
1.62 \\
1.45 \\
1.87 \\
1.26 \\
1.40 \\
1.31 \\
1.04 \\
1.62 \\
1.40 \\
1.18 \\
1.58\end{array}$ & $\begin{array}{r}+0.13 \\
+0.05 \\
+0.27 \\
+0.36 \\
+0.09 \\
+0.05 \\
+0.50 \\
+0.09 \\
+0.22 \\
+0.18 \\
0.00 \\
+0.36 \\
+0.13 \\
+0.14 \\
+0.36\end{array}$ & $\begin{array}{r}+9.5 \\
+5.4 \\
+25.7 \\
+36.0 \\
+5.8 \\
+3.5 \\
+36.4 \\
+7.6 \\
+18.6 \\
+15.9 \\
0.0 \\
+28.5 \\
+10.2 \\
+13.4 \\
+29.5\end{array}$ & $\begin{array}{l}1.27 \\
1.41 \\
1.88 \\
1.67 \\
1.92 \\
1.67 \\
1.49 \\
1.71 \\
1.80 \\
1.67 \\
1.49 \\
1.76\end{array}$ & \begin{tabular}{|c|} 
Not obtainable $\mathrm{f}$ \\
1.49 \\
1.50 \\
Not obtainable f \\
1.97 \\
1.58 \\
1.96 \\
Not obtainable f \\
1.58 \\
1.54 \\
1.75 \\
1.84 \\
1.89 \\
1.67 \\
1.98
\end{tabular} & $\begin{array}{c}\text { rom these films } \\
+0.22 \\
+0.09 \\
\text { rom these films } \\
+0.09 \\
-0.09 \\
+0.04 \\
\text { rom these films } \\
-0.09 \\
+0.05 \\
+0.04 \\
+0.04 \\
+0.22 \\
+0.18 \\
+0.22\end{array}$ & $\begin{array}{r}+17.3 \\
+6.3 \\
+4.7 \\
-5.6 \\
+2.0 \\
-5.6 \\
+3.3 \\
+2.3 \\
+2.2 \\
+13.1 \\
+12.0 \\
+12.5\end{array}$ \\
\hline \multirow[t]{3}{*}{$\begin{array}{l}\text { Mean } \\
\text { S.E. }\end{array}$} & $\begin{array}{r}1.17 \\
\pm 0.05\end{array}$ & $\begin{array}{r}1.36 \\
\pm 0.06\end{array}$ & $\begin{array}{l}+0.19 \\
\pm 0.03\end{array}$ & $\begin{array}{c}+16.4 \% \\
\pm 3 \cdot 1\end{array}$ & $\begin{array}{l}1.64^{*} \\
\pm 0.04\end{array}$ & $\begin{array}{l}1.72^{*} \\
\pm 0.04\end{array}$ & $\begin{array}{l}+0.08 * \\
\pm 0.02\end{array}$ & $\begin{array}{l}+5.3 \% \\
\pm 1.6\end{array}$ \\
\hline & \multirow{2}{*}{\multicolumn{4}{|c|}{$\begin{array}{l}\text { Corresponding mean figures in these } 12 \text { cases in expiration } \\
\text { Percentage increase of } \mathrm{A}-\mathrm{P} \text { diameter with inspiration }\end{array}$}} & $1 \cdot 20$ & $1 \cdot 39$ & & \\
\hline & & & & & $\begin{array}{c}0.44 \\
36.6\end{array}$ & $\begin{array}{c}0.33 \\
23 \cdot 7\end{array}$ & & \\
\hline
\end{tabular}

* Mean of 12 results.

(4) Effect of Head and Neck Extension UPON RESPIRATORY DISPLACEMENT OF LARYNX.In each posture, i.e., flexion and full extension, the respiratory displacement of the larynx with a full inspiratory movement was measured. It was thought that in head extension the respiratory displacement might be less, or that the larynx might even become elevated, due to the attachments of the larynx and hyoid bone to the base of the skull (Mitchinson and Yoffey, 1947), but in fact there is no significant difference between the respiratory displacement occurring in the headflexed and the head-extended positions. Thus, the mean inspiratory displacement in head flexion was a depression of $0.42 \mathrm{~cm}$. (S.E. $=0.14$ ) and in full head and neck extension a depression of $0.39 \mathrm{~cm}$. (S.E. $=0.16)$. The inspiratory displacement of the larynx, in fact, varied, and the subjects could be classified accordingly into three groups, namely, (1) inspiratory depression in eight of 15 subjects in head and neck extension (range 0.6 to $1.3 \mathrm{~cm}$.) and in nine of 15 in head and neck flexion (range 0.1 to $1.5 \mathrm{~cm}$.) ; (2) no change in position in four of 15 subjects in both the extended and flexed positions ; and (3) inspiratory elevation in three of 15 subjects in the extended position (range 0.1 to $0.8 \mathrm{~cm}$.) and in two of 15 in the flexed position (range 0.3 to $0.4 \mathrm{~cm}$.).

\section{Discussion}

Assuming that there is full inferior movement of the lung root with a deep inspiratory movement, then if this were also associated with full extension of the head and neck, the total extension of the trachea would be about $5 \mathrm{~cm}$., of which $2.5 \mathrm{~cm}$. would be due to extension superiorly associated with the extended posture, and $2.5 \mathrm{~cm}$. due to extension inferiorly assoziated with the inspiratory movement of the carina. These two factors would, theoretically, extend the trachea of the average adult male $(12 \mathrm{~cm}$. according to Testut and Latarjet, 1949) by about $41 \%$ of its resting length if they act concomitantly. The adult human trachea, at the age of the subjects in this study, can be extended in vitro by almost $40 \%$ of its unextended length (Harris, 1958). However, it is unlikely that this amount of extension occurs in vivo, and it was thought that head and neck extension probably inhibits the inspiratory descent of the carina, either by actual mechanical limitation or through reflex inhibition of respiratory movement resulting from stimulation of stretch receptors in the trachea.

To investigate this point, observations were made upon six patients undergoing routine bronchography and in whom the bronchograms were substantially normal. It was found that in each instance the level of the carina after the deepest inspiratory effort was consistently higher when the head and neck were extended than when they were flexed. Thus the carina was, on the average, $1.1 \mathrm{~cm}$. (S.E. $0.4 \mathrm{~cm}$., range $0.3 \mathrm{~cm}$. to $2.5 \mathrm{~cm}$.) higher at the end of an inspiratory movement made when the head and neck were extended than when they were flexed. Also extension of the head and neck produced an 
elevation of the carina in each instance (mean elevation $1.8 \mathrm{~cm}$., S.E. $0.2 \mathrm{~cm}$., range 1.1 to $2.7 \mathrm{~cm}$.), the measurements being made in the phase of full expiration.

The mean respiratory displacement of the larynx with a deep inspiratory movement was about $0.4 \mathrm{~cm}$. and this could account for about $16 \%$ of the inferior inspiratory displacement of the carina with a deep inspiratory movement. The findings suggest that most of the inferior displacement of the carina occurs by extension of the trachea. The maximal inferior inspiratory displacement of the larynx was $1.5 \mathrm{~cm}$., which could account for $60 \%$ of the inferior inspiratory displacement of the carina with a deep inspiratory movement.

From Table II it can be seen that the inspiratory increase of the antero-posterior diameter of the trachea was about $36 \%$ when the head was extended and $24 \%$ when the head was flexed (cf. Holden and Ardran, 1957), so that head extension did not prevent inspiratory widening of the trachea.

When interpreting changes upon singleexposure radiographs, it should be realized that a dynamic phenomenon is being analysed: one assumes that the most representative phase of the phenomenon is recorded upon that particular film. It may be that a film, taken at the phase of full inspiration, may only record a position of stability, this position being due to the elastic recoil of the passage from some extreme a little beyond the point of stability. The findings are submitted with this reservation in mind.

\section{SUMmaRY AND CONCLUSIONS}

The effect of head and neck extension upon elongation of the trachea and of the infrahyoid respiratory passage at the extremes of inspiration and expiration was investigated radiographically. The observations are based upon measurements. taken from radiographs of 15 healthy young adult males aged 18-22 years. The findings resulting from head and neck extension were as follows:

(1) There was an elongation of the infrahyoid respiratory passage, i.e., the distance between the superior surface of the hyoid bone and the inferior border of the lamina of the thyroid cartilage, by 23 to $30 \%$ of its initial length.

(2) The trachea was stretched by about $2.6 \mathrm{~cm}$., an amount equivalent to the inferior respiratory displacement of the tracheal bifurcation on deep inspiration.

(3) The antero-posterior diameter of the supraclavicular portion of the trachea was significantly narrowed (16\%) and was more marked in the phase of expiration.

(4) The respiratory displacement of the larynx $\overrightarrow{\vec{A}}$ was not affected. In several cases there was inspiratory depression of the larynx, in a lesser number elevation and, least often, no respiratory $\sigma$ displacement (this agrees with the findings of 9 Mitchinson and Yoffey, 1947). The mean inspiratory displacement of the larynx was $0.4 \mathrm{~cm}$. depression which could account for $16 \%$ of the inferior inspiratory displacement of the carina with a full inspiratory movement.

(5) The effect of head and neck extension upon the position and the respiratory movement of the carina was investigated in six patients. Extension of the head and neck restricted the inferior inspiratory level attained in each instance and measurements made in the phase of full expiration showed an elevation of the carina in each instance with head and neck extension.

I am very grateful to Dr. J. H. Middlemiss for his interest and advice, also for facilities in the Department of Radiodiagnosis, Bristol Royal Infirmary, and to Mr. S. E. Cooke, Senior Radiographer, for his ready assistance ; to Dr. K. H. Gaskell for facilities in the Thoracic Radiography Department, Frenchay Hospital, Bristol, and also to the radiographers of that department ; to Professor J. M. Yoffey for his interest and encouragement; to the medical students who volunteered for the radiographic studies; and to Mr. K. W. Keohane for advice upon the correction factor.

\section{REFERENCES}

Brückner, H. (1952). Z. Anat. Entwickl. Gesch., 116, 276. Harris, R. S. (1958). Unpublished data.

Holden, W. S., and Ardran, G. M. (1957). J. Fac. Radiol., 8, 267. Macklin, C. C. (1925). Amer. J. Anat., 35, 303.

Mitchinson, A. G., and Yoffey, J. M. (1947). J. Anat. (Lond.), 81, 118.

Testut, $L_{\text {. }}$ and Latarjet, A. (1949). Traité d'Anatomie Humaine, 9 th $\frac{\odot}{8}$ ed., Vol. 3, p. 945 . Doin, Paris. 